\title{
Association between Vitamin D Deficiency and Preterm: A Case Control Study
}

\author{
Shereif Mohammed Abd El Hameed ${ }^{1}$, Dina Yahia Mansour ${ }^{1}$, Heba Mohamed Adel Abou Zaghla ${ }^{2}$ \\ Seham Hasan Rishi ${ }^{{ }^{*}}$ \\ ${ }^{1}$ Department of Obstetrics and Gynecology, Faculty of Medicine, Ain Shams University \\ ${ }^{2}$ Department of Clinical and Chemical Pathology, Faculty of Medicine, Ain Shams University \\ *Corresponding Author: Seham Hasan Rishi, Phone No.: (+2) 01014176642,E-mail: seham.rishi77@gmail.com
}

\begin{abstract}
Background: Preterm labor refers to the delivery before 37th week of pregnancy. The World Health Organization (WHO) reported that about 15 million neonates are born preterm with about 1 million deaths occur during infancy. PTB infants who survive frequently suffer from chronic pulmonary diseases and learning deficits, causing heavy burdens for society and family. Preterm birth is one of the most serious medical complications of pregnancy.
\end{abstract}

Purpose: to compare serum 25 hydroxy vitamin D levels among patients with preterm delivery and women who have full term birth.

Patients and Methods: a case-control study was conducted at Ain Shams University Maternity Hospital from December 2017 to May 2018. It was carried out on 138 women post delivery recruited, they were divided into group of patients with preterm babies and other group with full term babies, 69 women in each.

Results: Mean level of 25 hydroxy vitamin D between preterm birth group was $4.4 \pm 2.5 \mathrm{ng} / \mathrm{ml}$ and between full term birth group was $24.9 \pm 13.74 \mathrm{ng} / \mathrm{ml}$. Therefore, according to student $\mathrm{T}$ test and chisquare test, the current study found that there is significant difference in serum 25 hydroxy vitamin D levels between women with preterm birth and women with full term birth preterm birth.

Conclusion: from this study it can be concluded that vitamin D assay can be used for prediction of preterm birth and vitamin D supplementation can be used routinely in prevention of preterm birth.

Keywords: Preterm Labor - Preterm Birth - Tansvaginal Ultrasound

\section{Introduction}

Preterm birth (PTB) is the birth of a baby before completed 37 weeks of gestation. Every year, 15 million neonates worldwide are born preterm preterm birth (PTB), as the largest cause of neonatal deaths worldwide puts surviving children at risk for cerebral palsy, behavioral problems, bronchopulmonary dysplasia, retinopathy of prematurity, hearing impairments, increased hospital admissions and academic underachievement ${ }^{(\mathbf{1})}$.

Vitamin D is a fat-soluble metabolite required for the proper regulation of many body systems, as well as normal human growth and development. Vitamin D efficiency is considered as a common and thorny public health problem around the world, especially for pregnant women ${ }^{(2)}$.

Maternal vitamin D deficiency, or insufficiency, has been demonstrated to be related to variety of adverse maternal and fetal outcomes, including gestational diabetes mellitus (GDM), preeclampsia and small for gestational age $^{(2)}$.

Prematurity is not only a huge medical problem but also a social and economic one.

There have been some studies describing the association between maternal vitamin D levels and preterm birth; however their results are conflicting. According to some studies, vitamin D deficiency during pregnancy is associated with an increasing risk of preterm birth. Wagner et al. ${ }^{(3)}$ reported that pregnant women with serum concentrations of vitamin D less than $20 \mathrm{ng} / \mathrm{mL}$ had 3.81times the odds of a preterm birth compared to those with serum concentrations of vitamin D greater than 40ng/ mL. Bodnar et al. (4) reported that the risk of preterm birth decreased significantly as serum concentrations of 25-hydroxyvitamin D increased to approximately $36 \mathrm{ng} / \mathrm{mL}$ and then plateaued. As reported by Shibata et al. ${ }^{(5)}$ lower levels of vitamin D among pregnant women are associated with premature delivery in Japan. In contrast Zhou et al. ${ }^{(6)}$ reported that vitamin $\mathrm{D}$ deficiency was associated with a reduced risk of preterm birth. They found 
that the prevalence of preterm delivery in the high-level (maternal $25(\mathrm{OH}) \mathrm{D} \geq 30 \mathrm{ng} / \mathrm{mL}$ ) was higher than that in the low $(\leq 20 \mathrm{ng} / \mathrm{mL})$ and medium $(20-30 \mathrm{ng} / \mathrm{mL}$ ) level groups in southern China. However, other studies have demonstrated no association between vitamin D status and preterm birth. Rodriguez et al. ${ }^{(7)}$ found that vitamin $\mathrm{D}$ deficiency during pregnancy was not associated with preterm birth.

Aim of the work

To compare serum 25 hydroxy vitamin $\mathrm{D}$ levels among patients with preterm delivery and women who have full term birth.

\section{Patients and Methods}

Type of study:

The study was designed as a case control study.

\section{Study setting}

This study was conducted at Ain Shams University Maternity Hospital.

\section{Study period:}

The study was done from December 2017 until May 2018 after approval of the research ethics committee.

\section{Sample size justification}

The required sample size has been calculated using the power analysis and sample size 2008 software version 08.0.15 ${ }^{(8)}$.

The primary outcome measures the proportion of patients with severe vitamin D deficiency (defined as vitamin D level $<10 \mathrm{ng} / \mathrm{mL}$ ) in either study group.

A previous study reported that the prevalence of sever vitamin D deficiency among women with or without preterm labor (PTL) was approximately $34 \%$ versus $14 \%$ respectively ${ }^{\left({ }^{(3)}\right.}$.

So, it is estimated that a sample size of 69 patients per group (total.138 patients) would achieve a power of $80 \%$ (type 2 errors. $0.2)$ to detect a statistically significant difference of $20 \%$ between the 2 groups as regards the proportion of patients with severe vitamin $\mathrm{D}$ deficiency using a two-sided chisquared test with a confidence level of $95 \%$ (type I error. 0.05).

\section{Study population}

- This study was conducted on (138) women. They were subdivided into two groups:

1. Control group: 69 women, delivered term babies at (38-42 weeks).

2. Patients group: 69 women, delivered preterm babies (less than 37weeks).

\section{- Inclusion criteria:}

1. Singleton gestation.

2. Maternal age: 20-35 years.

- Exclusion criteria:

1. Multi fetal pregnancy.

2. Anatomical or genetic defect of the fetus.

3. Iatrogenic preterm delivery.

4. Maternal medical disorder e.g diabetes millets (D.M).

5. Antepartum hemorrhage.

6. Hypertensive disorders.

7. Polyhydromins or oligolydromins

8. Premature rupture of membranes \pm Chorioamnionitis

9. Incompetent cervix.

10. Post IVF.

11. Uterine Fibroid or malformation.

All patients in the two groups were subjected to:

1. Consent: A written informed consents were taken from all cases of the two groups after full explanation of steps and significance of this study.

\section{Full history taking:}

History: patient diagnosis was recorded and full history was taken from the patients including: detailed personal, present, menstrual, obstetric, past and family histories, chronic medical illnesses, and surgical histories.

\section{Complaint and history of this delivery:}

i. Onset of labour pain and duration.

ii. Presence of any discharge or bleeding.

iii. History of truma or infection.

iv. Associated symptoms.

v. History of previous admission to hospital and the cause.

vi. Presence of regular antenatal care or not?

\section{Obstetric history:}

For each previous delivery.

- Number.

- Antepartum and post partum complication.

- History of previous preterm delivery.

\section{Examination:}

i. Heart rate, temperature, respiratory rate, and blood pressure:

ii. Body weight, height. 


\section{Laboratory investigation:}

i. Complete blood count (CBC): blood sample was collected into a test tube containing anticoagulant (EDTA).

ii. Blood sugar.

iii. Vitamin D assay:

All samples were screened by 25 hydroxy (25-OH) vitamin D ELISA for measurement of total 25-OH vitamin D (vitamin $\mathrm{D}_{2}$ and vitamin $\mathrm{D}_{3}$ ) in serum. The kit name: (The Calbiotech, Inc. 25-hydroxy (25$\mathrm{OH})$ Vitamin D ELISA was used as manufacturer`s instructions.

\section{Sample collection and preparation:}

Blood samples $(5 \mathrm{ml})$ were collected by venipuncture into test tube with no additives, clotting was allowed then centrifuged for 10 minutes at $5.000 \mathrm{~g}$ to separate the serum at laboratory of obstetrics and gynecology department. Serum was transported to be frozen at $-20^{\circ} \mathrm{C}$ at laboratory of microbiology and Immunology department at Faculty of Medicine, Ain Shams University for testing.

\section{Data Management and Analysis:}

The collected data was revised, coded, tabulated and introduced to a PC using Statistical package for Social Science ((IBM Corp. Released 2011. IBM SPSS Statistics for Windows, Version 20.0. Armonk, NY: IBM Corp). Data was presented and suitable analysis was done according to the type of data obtained for each parameter.

\section{Results}

Table (1): Comparison between the two study groups as regard vital data

\begin{tabular}{|c|c|c|c|c|c|c|}
\hline \multirow{2}{*}{} & \multicolumn{4}{|c|}{ Group } & \multirow{2}{*}{ P } & \multirow{2}{*}{ Sig } \\
\cline { 2 - 5 } & Mean & $\mathbf{\pm S D}$ & Mean & $\mathbf{\pm S D}$ & & \\
\hline SBP & 116.09 & 6.91 & 117.97 & 6.08 & $0.09^{*}$ & NS \\
\hline DBP & 75.00 & 4.77 & 76.30 & 4.59 & $0.10^{*}$ & NS \\
\hline Pulse & 78.39 & 10.02 & 79.74 & 8.16 & $0.38^{*}$ & NS \\
\hline Temperature & 36.70 & .29 & 36.86 & .25 & $0.001^{*}$ & HS \\
\hline
\end{tabular}

$\mathrm{SBP}=$ Systolic blood pressure, $\mathrm{DBP}=$ Diastolic blood pressure $*$ Student $\mathrm{t}$ test

There was no significant difference between study groups as regard mothers' blood pressure and pulse. However preterm group mothers had a significantly lower body temperature.

Table (2): Comparison between the two study groups as regard lab data

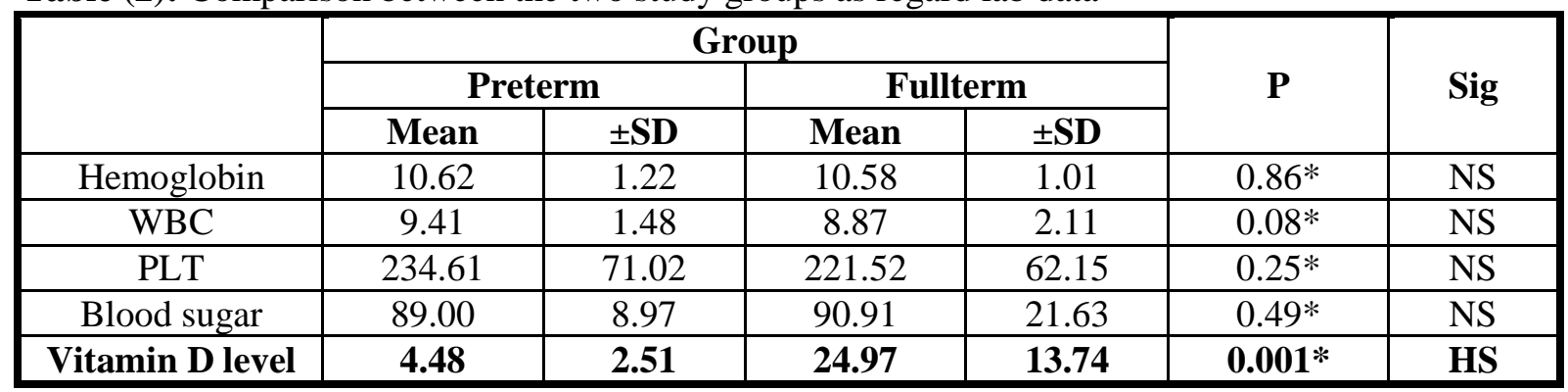

*Student $\mathrm{t}$ test

There was no significant difference between study groups as regard mothers' lab data. However preterm group mothers had a significantly lower serum vitamin D level with a mean of $4.48 \pm 2.5$ compared to $24.9 \pm 13.7$ among full term mothers. 
Table (3): Comparison between the two study groups as regard obstetric data

\begin{tabular}{|c|c|c|c|c|c|c|c|c|c|}
\hline & \multicolumn{6}{|c|}{ Group } & \multirow{3}{*}{$\mathbf{P}$} & \multirow{3}{*}{ Sig } \\
\hline & & \multicolumn{3}{|c|}{ Preterm } & \multicolumn{3}{|c|}{ Full term } & & \\
\hline & & Mean & \pm SD & Median(IQR) & Mean & \pm SD & Median(IQR) & & \\
\hline \multicolumn{2}{|c|}{ Gestational Age } & 33.49 & 2.36 & $34(33-35$ & 38.46 & 1.13 & $38(38-39)$ & $0.001 *$ & HS \\
\hline \multicolumn{2}{|c|}{ Parity } & 2.25 & 1.12 & $2 .(1-3)$ & 2.48 & 1.07 & $3(2-3)$ & 0.172 ** & $\mathrm{NS}$ \\
\hline \multirow{2}{*}{$\begin{array}{l}\text { Mode of } \\
\text { Delivery }\end{array}$} & NVD & 39 & $56.5 \%$ & & 29 & $42.0 \%$ & & \multirow{2}{*}{$0.089^{\ddagger}$} & \multirow{2}{*}{ NS } \\
\hline & $\mathrm{C} / \mathrm{S}$ & 30 & $43.5 \%$ & & 40 & $58.0 \%$ & & & \\
\hline \multirow{2}{*}{ Abortion } & No & 39 & $56.5 \%$ & & 42 & $60.9 \%$ & & \multirow{2}{*}{$0.604^{*}$} & \multirow{2}{*}{ NS } \\
\hline & Yes & 30 & $43.5 \%$ & & 27 & $39.1 \%$ & & & \\
\hline
\end{tabular}

*Student $\mathrm{t}$ test

**Mann Whitney test

$\$$ Chi square test

There was no significant difference between study groups as regard parity, Mode of Delivery or history of abortion. However, a significant difference between study groups was found regarding Gestational age.

Table (4): Comparison between the two study groups as regard fetal weight and sex

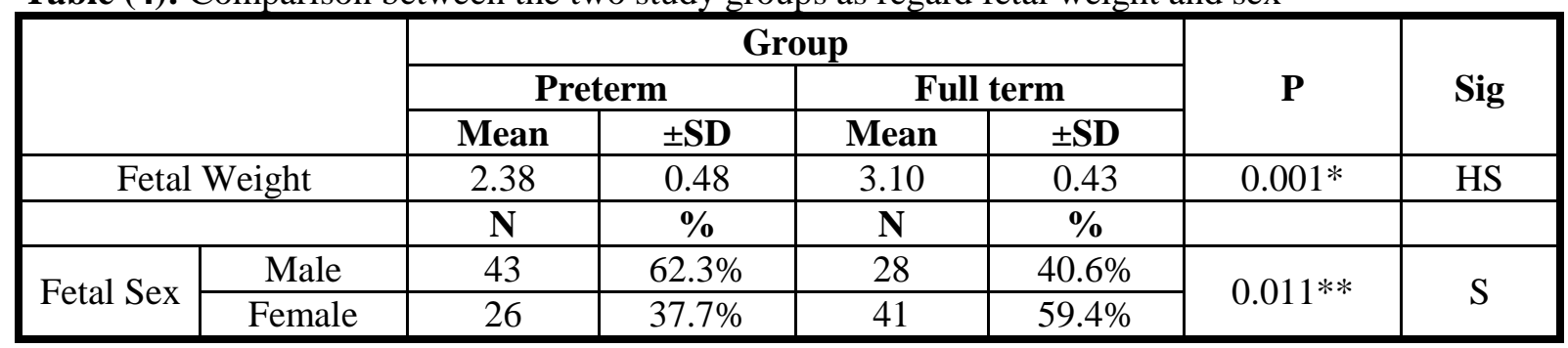

*Student $t$ test

**Chi-Square Tests

There was a highly significant difference between study groups as regard fetal weight and sex.

Table (5): Relation between mode of delivery, previous abortion, fetal sex and vitamin D level among preterm group

\begin{tabular}{|c|c|c|c|c|c|c|}
\hline & & \multicolumn{3}{|c|}{ Vitamin D level } & \multirow{2}{*}{$\mathbf{P}$} & \multirow{2}{*}{ Sig } \\
\hline & & Mean & $\pm \mathrm{SD}$ & Median(IQR) & & \\
\hline \multirow{2}{*}{$\begin{array}{l}\text { Mode of } \\
\text { Delivery }\end{array}$} & NVD & 4.21 & 2.48 & $3(2.5-5)$ & \multirow{2}{*}{$0.123^{* *}$} & \multirow{2}{*}{ NS } \\
\hline & $\mathrm{C} / \mathrm{S}$ & 4.83 & 2.55 & $5(3-7)$ & & \\
\hline \multirow{2}{*}{ Abortion } & No & 3.68 & 2.02 & $3(2-5)$ & \multirow{2}{*}{$0.005^{*}$} & \multirow{2}{*}{ HS } \\
\hline & Yes & 5.52 & 2.73 & $5(3-7)$ & & \\
\hline \multirow{2}{*}{ Fetal Sex } & Male & 4.35 & 2.22 & $4(2-7)$ & \multirow{2}{*}{$0.817 * *$} & \multirow{2}{*}{ NS } \\
\hline & Female & 4.69 & 2.96 & $3.5(3-7)$ & & \\
\hline
\end{tabular}

*Student $t$ test

**Mann Whitney test

There was no significant difference between each of mode of delivery, fetal sex and vitamin D level among preterm group, while a significant difference was detected between those with and without history of abortion as regard vitamin D level. 
Table (6): Relation between each of mode of delivery, previous abortion, fetal sex and vitamin D level among full term group

\begin{tabular}{|c|c|c|c|c|c|c|}
\hline & & \multicolumn{3}{|c|}{ Vitamin D level } & \multirow{2}{*}{$\mathbf{P}$} & \multirow{2}{*}{ Sig } \\
\hline & & Mean & \pm SD & Median (IQR) & & \\
\hline \multirow{2}{*}{ Mode of Delivery } & NVD & 21.66 & 12.44 & $18(10-30)$ & \multirow{2}{*}{$0.123 * *$} & \multirow{2}{*}{ NS } \\
\hline & $\mathrm{C} / \mathrm{S}$ & 27.37 & 14.28 & $25(18-35)$ & & \\
\hline \multirow{2}{*}{ Abortion } & No & 28.24 & 14.63 & $29(18-35)$ & \multirow{2}{*}{$0.007 *$} & \multirow{2}{*}{ HS } \\
\hline & Yes & 19.89 & 10.60 & $18(15-22)$ & & \\
\hline \multirow{2}{*}{ Fetal Sex } & Male & 22.68 & 11.90 & $19(13-31)$ & \multirow{2}{*}{$0.286^{* *}$} & \multirow{2}{*}{ NS } \\
\hline & Female & 26.54 & 14.80 & $22(18-35)$ & & \\
\hline
\end{tabular}

*Student t test

**Mann Whitney test

There was no significant difference between each of mode of delivery, fetal sex and vitamin $\mathrm{D}$ level among full term group, while a significant difference was detected between those with and without history of abortion as regard vitamin D level.

\section{Discussion}

Vitamin D deficiency is a significant obstetric problem and is an important cause of maternal and neonatal morbidity. In comparison to term infant, preterm infant is at risk of mortality and a variety of health and developmental problems. According to world health organization, about 15 million babies born preterm annually which is more than 1 in 10 babies. Among those one million children die yearly due to complications of prematurity; and many of those who survive have disability, like learning, visual and hearing disabilities. The objective of this study is to assess the association between vitamin D deficiency and preterm delivery ${ }^{(8)}$.

In the present study there were no significant differences between study groups regarding their age, weight, blood group, blood pressure, pulse, hemoglobin level, WBC, PLT, blood sugar, parity, mode of delivery and history of abortion. On the other hand, the present study showed significant differences between the study groups regarding their body temperature, Vit D level, gestational age, fetal weight and fetal sex. The current study also reported that Vitamin D level could be used in the prediction of preterm labour at a cut off level of $\leq 7$, with $91.3 \%$ sensitivity and $100 \%$ specificity.

The present study showed that there is no difference in age, mother weight, parity, fetal weight between patients with low or normal vitamin D level.
The results of Bodnar et al. ${ }^{(4)}$ study which showed that there was no difference in age between study groups (group with normal vitamin $\mathrm{D}$ and those with vitamin $\mathrm{D}$ deficiency). The same study also found association between low vitamin D level during early gestational age (at 20 week gestation) and preterm delivery. This association exists after adjustment of confounders like pre-pregnancy body mass index, race, educational level, marital status and smoking ${ }^{(4)}$.

In their study of maternal vitamin D status at 23-28 weeks of gestation, Zhao et al. (9) found the age mean \pm SD of their participants was $27.3 \pm 3.9$ years respectively. In contrast to our study finding, they found association between maternal age and serum level of vitamin D and lowest level was among women who are 35 years old, $p$ value was < 0.001 . Also, they found difference in vitamin $\mathrm{D}$ level and pre-pregnancy maternal weight (they measure body mass index), pregnant women who were overweight prior to pregnancy had lower serum vitamin $\mathrm{D}$ level $p$ value was $<0.001$. In addition, they found no association between maternal serum level of vitamin $\mathrm{D}$ and preterm delivery $p$ value $=0.489$ ${ }^{(9)}$. In our study there was no difference among study groups regarding their systolic and diastolic blood pressure, however, Zhao et al. ${ }^{(9)}$ found low serum maternal blood of vitamin $\mathrm{D}$ is associated with increased risk of preeclampsia after adjusting for confounders (maternal age, parity, pre-pregnancy BMI and season of maternal blood sampling), odds ratio was 3.16 , and $95 \%$ confidence interval was $1.77-5.65^{(9)}$.

Regarding Vit D, the result of the current study reported that preterm group 
mothers had a significantly lower serum vitamin $\mathrm{D}$ level with a mean of $4.48 \pm 2.5$ compared to $24.9 \pm 13.7$ among full term mothers. Bodnar et al. ${ }^{(4)}$ reported that the mean level of vitamin D among study groups was $82.7 \mathrm{nmol} /$, standard deviation was 31.5 $\mathrm{nmol} / \mathrm{L}$ and the median was $85.7 \mathrm{nmol} / \mathrm{L}$; this is different from our result ${ }^{(4)}$. This difference could be due to study design as they studied vitamin $\mathrm{D}$ among women who had twins pregnancies only and it was interventional study.

In Meta-analysis of observational studies done by Qin et al. ${ }^{(10)}$ there were total eleven studies out of 237 studies were included in this meta-analysis study; six studies conducted in the United States of America, tow in Spain, and one in Australia, China, and Canada. In this meta-analysis, they found pregnant women with low vitamin D level increase their risk of preterm delivery, and the Odds ratio is $1.29 ; 95 \%$ confidence interval is $1.16,1.45^{(10)}$. Cochrane Review showed that vitamin D supplementation in pregnancy decreases the incidence of low birth weight $(<2.5 \mathrm{~kg})$ by $52 \%$. In the same way, in Meta-analysis of 24 observational studies by Wei et al. ${ }^{(11)}$ they found association between maternal serum level of vitamin D less than 50 $\mathrm{nmol} / \mathrm{l}$ and preterm delivery ${ }^{(11)}$.

Wagner et al. ${ }^{(12)}$ found difference between study groups regarding parity; intervention group (who receive vitamin D during study because they are deficient in vitamin D) tend to has higher parity than women who are control groups, Also, they found supplementation of vitamin $\mathrm{D}$ to intervention group does not decrease risk of preterm delivery ${ }^{(12)}$. This finding is opposite to this study finding, this is because our study is observational study and their study is interventional study.

Another study by Wagner et al. (3) discovered during post-hoc comparison using correlation and logistic regression to measure the strength of the association between serum vitamin $\mathrm{D}$ at 3 time points (during first trimester, second trimester and third trimester) serum vitamin $\mathrm{D}$ level closer to delivery is more strongly connected with gestational age at delivery than earlier values. Also, they discover pregnant women with low level of vitamin $\mathrm{D}$ at third trimester $(<20 \mathrm{ng} / \mathrm{mL})$ had
3.81 times the odds of a preterm delivery (after adjusting for race and ethnicity) than those with serum concentrations of vitamin D more than $40 \mathrm{ng} / \mathrm{mL}$; and at second trimester, the odds were 2.0 fold. In addition, they found serum level of vitamin $\mathrm{D}$ of $40 \mathrm{ng} / \mathrm{mL}$ is associated with $47 \%$ decrease in preterm births (3)

However, in this study serum level of less $\leq 9 \mathrm{ng} / \mathrm{mL}$ not $<20 \mathrm{ng} / \mathrm{mL}$ is used in prediction of preterm delivery. This difference in the cut level of vitamin D level could be due to difference assays were used to measure serum level of vitamin D. Also, in another Post-hoc analysis of the relationship between serum vitamin D level and preterm birth rates in the National Institute of Child Health and Human Development (NICHD) and Thrasher Research Fund (TRF) studies with comparison to Charleston County, South Carolina March of Dimes (CCMOD), there was an association of serum vitamin D level within six weeks of delivery and preterm delivery, and in comparison to serum level of $\leq 20 \mathrm{ng} / \mathrm{ml}$, level of $\geq 40 \mathrm{ng} / \mathrm{ml}$ is strongly associated with reduced risk of preterm birth by about $57 \%{ }^{(3)}$.

Similar to our finding, in their study of 93 Japanese pregnant women, Shibata et al. ${ }^{(5)}$ found about 85 pregnant women $(91.35 \%)$ have serum vitamin D level less than $20 \mathrm{ng} / \mathrm{ml}$, and there was association of low vitamin level and preterm delivery ${ }^{(5)}$.

Andersen et al. ${ }^{(13)}$ showed that among 2874 women who participated in Odense Child Cohort study, there was a strong association between low maternal serum vitamin $\mathrm{D}$ and risk of first trimester abortion (as primary outcome), the risk of first trimester abortion is about >2-fold (odds ratio: 2.50; 95\% confidence interval is1.10- 5.69) ${ }^{(13)}$.

In contrast to our finding, a prospective cohort study in Spain conducted by Rodriguez et al. ${ }^{(7)}$ found no association between vitamin $\mathrm{D}$ status in pregnancy and preterm delivery after adjustment of confounders $(P$-values $>0.4)$. But similar to what we discover, they found no association between maternal serum level of vitamin $D$ and fetal birth weight $(P$-values $>0.3)$ or mode of delivery (whether normal vaginal delivery of by caesarean section $(P$-value $=0.695){ }^{(7)}$. Also, Flood-Nichols et al. ${ }^{(14)}$ found no association between low maternal serum 
vitamin $D$ and preterm delivery and spontaneous abortion, odds ratio was1.01 ( $p$ value $=0.738,95 \%$ Confidence Interval was $0.947-1.164^{(14)}$.

In opposite to our study, Gernand et al. ${ }^{(15)}$ discovered in their study that the mean level of serum vitamin D among participants was $51.3(20 \mathrm{ng} / \mathrm{ml})$ and standard deviation was $28 \pm \mathrm{SD} n \mathrm{nmol} /$ liter. After adjustment for trimester, maternal blood drawn, maternal race/ethnicity, pre-pregnancy BMI, height, smoking, season, and study site, they found increase in fetal birthweight by 3.6 gram $P$ value was 0.014 (95\% confidence interval is 1.1-6.1) to every $1 \mathrm{nmol} /$ liter increase in maternal serum vitamin $D$ up to $37.5 \mathrm{nmol}$ /liter, then the increases will be off ${ }^{(\mathbf{1 5})}$.

In contrast to our finding, the result of nested case-control study of first-trimester maternal vitamin D level by Baker et al. ${ }^{(16)}$ showed no difference in prevalence of early pregnancy vitamin $\mathrm{D}$ deficiency (defined as vitamin $\mathrm{D}<20 \mathrm{ng} / \mathrm{mL}$ ) between women delivering preterm or at term. This difference in the result is related to their sample size, which was larger (totally 160 women, 40 cases, and 120 control; the prevalence of vitamin $\mathrm{D}$ deficiency in the cohort was only $6.9 \%$, with 11 of 160 women). Likewise, Wetta et al. ${ }^{(17)}$ found after adjusting for cofounders (age, race, parity, weight, prior preterm birth and season of specimen collection), there was no association between deficiency(less than $15 \mathrm{ng} / \mathrm{ml}$ ) or insufficiency (less than $30 \mathrm{ng} / \mathrm{ml}$ ) of vitamin D during midtrimester and preterm delivery (prior to 35 week gestation) similarly there was no association of vitamin D and preeclampsia at less than 37 weeks gestation (in our study there was on difference in systolic and diastolic blood pressure among the study groups ${ }^{(17)}$.

In our results there was no association between maternal serum vitamin $\mathrm{D}$ level and fetal sex. However, study by Gernand et al. ${ }^{(15)}$ found there were relations between vitamin D and placental vascular pathology which difference by infant sex. They found dissimilarities by infant sex, mothers with high serum vitamin D level $(\geq 80 \quad \mathrm{nmol} / \mathrm{L})$ associated with $49 \%$ reduced risk of developing a vascular pathology in the placenta in pregnancies in comparison to women with insufficient vitamin D level $(<50$ $\mathrm{nmol} / \mathrm{L}$ ) if they were pregnant by male infant; and those women with normal serum vitamin D level in comparison to those with insufficient level had $44 \%$ reduced risk of placental vascular pathology (95\% confidence interval is $0.45-0.97$ ). This association was not existed if women were pregnant by female infant ${ }^{(15)}$.

Even though there is no association between vitamin $\mathrm{D}$ level and fetal sex, fetal weight among both study groups, however, preterm babies tend to have low birth weight and most of them were males.

\section{Conclusion}

Maternal low level of vitamin D is significantly associated with risk of preterm delivery, but not associated with maternal age, weight, and fetal birth weight.

\section{References}

1. Blencowe H, Cousens S, Oestergaard M et al. (2012): National, regional and worldwide estimates of preterm birth. Lancet, 379(9832): 2162-72.

2. Holick MF (2007): Vitamin D deficiency. N Engl J Med., (357): 266281.

3. Wagner CL, Baggerly C, McDonnell SL et al. (2015): Post-hoc comparison of vitamin $D$ status at three time points during pregnancy demonstrates lower risk of preterm birth with higher vitamin $\mathrm{D}$ closer to delivery. J. Steroid Biochem. Mol. Biol., 148: 256-260.

4. Bodnar LM, Platt RW and Simhan HN (2015): Early pregnancy vitamin D deficiency and risk of preterm birth subtypes. Obstet. Gynecol., 125: 439447.

5. Shibata M, Suzuki A, Sekiya T et al. (2011): High prevalence of hypovitaminosis D in pregnant Japanese women with threatened premature delivery. Bone Miner Metab., 29(5): 61520.

6. Zhou J, Su LY, Coa X et al. (2014): Association between 25-hydroxy vitamin D level and pregnancy outcomes: proactive observation observational Study 
in southern China. Eur J. Clin Nutr., 925930.

7. Rodriguez A, García-Esteban R, Basterretxea M et al. (2015): Associations of maternal circulating 25hydroxyvitamin D3 concentration with pregnancy and birth outcomes. BJOG., 122(12): 1695-704.

8. Baczyfiska-Strzecha $M$ and Kalinka $J$ (2017): Assessment of correlation between vitamin $\mathrm{D}$ level and prevalence of preterm births in the population of pregnant women in Poland. Int $\mathrm{J}$ Occup Med Environ Health, 30(6); 933-941.

9. Zhao X, Fang R, Yu R et al. (2017): Maternal Vitamin D Status in the Late Second Trimester and the Risk of Severe Preeclampsia in Southeastern China. Nutrients, 9(2): 138-143.

10. Qin LL, Lu FG, Hui $S$ et al. (2016): Does Maternal Vitamin D Deficiency Increase the Risk of Preterm Birth: AMeta-Analysis of Observational Studies. Nutrients, 8(5): 301.

11. Wei SQ, Qi HP, Luo ZC et al. (2013): Maternal vitamin D status and adverse pregnancy outcomes: a systematic review and meta-analysis. Maternal-Fetal \& Neonatal Medicine, 26(9): 889-899.

12. Wagner CL, Rebecca BM, Donna DJ et al. (2013): Health Characteristics and Outcomes of Two Randomized Vitamin
D Supplementation Trials during Pregnancy: A Combined Analysis. J Steroid Biochem Mol Biol., 136: 313320.

13. Andersen LB, Jørgensen JS, Jensen TK et al. (2015): Vitamin D insufficiency is associated with increased risk of first-trimester miscarriage in the Odense Child Cohort. The American Journal of Clinical Nutrition, 102(3): 633-638.

14. Flood-Nichols SK, Tinnemore D, Huang RR et al. (2015): Vitamin D deficiency in early pregnancy. Plos One, 10(4): e0123763.

15. Gernand AD, Bodnar LM, Klebanoff MA et al. (2013): Maternal serum 25hydroxyvitamin $\mathrm{D}$ and placental vascular pathology in a multicenter US cohort. Am J Clin Nutr., 98(2): 383-404.

16. Baker AM, Haeri S, Camargo CA et al. (2011): A nested case-control study of first-trimester maternal vitamin D status and risk for spontaneous preterm birth. American Journal of Perinatology, 28(9): 667.

17. Wetta LA, Biggio JR, Cliver $S$ et al. (2014): Is Midtrimester Vitamin D Status Associated with Spontaneous Preterm Birth and Preeclampsia? Am J Perinatol., 31(6): 541-546. 